\title{
DESIGNING THE ENTRANCES OF RESIDENTIAL BUILDINGS, BETWEEN ORIGINALITY AND CONTEMPORANEITY TO ACHIEVE SUSTAINABILITY STANDARDS.
}

\author{
Ayat Abdalla Fawaz \\ Lecturer - Décor Department - Faulty Of Fine Arts-Alexandria University \\ The Arab Republic of Egypt-Alexandria government-email:ayat.fawaz@alexu.edu.eg
}

\begin{abstract}
:
The design of the entrances to the residential buildings is one of the most important impressions that affect man upon entering the dwelling, as well as it has many cultural, material, and social connotations for the owners of the residential buildings.

And when studying models of the entrances of traditional Islamic buildings in the Mamluk and Ottoman eras, we find an elegant taste and commitment to many design criteria, the most important of which is achieving privacy and achieving social and environmental sustainability standards for individuals, compared to what we see today in terms of designing residential entrances of contemporary buildings.

As we find that many of the contemporary entrances neglect the achievement of sustainability standards and at the same time neglect the achievement of aesthetic standards.

Therefore, we seek in this research to reach aesthetically and environmentally designs criteria, to achieve a good design for the entrance of residential buildings in Egypt, through the use of the analytical and comparative approach between the models presented in traditional Islamic residential buildings, and modern residential buildings in Egypt, and compare them with international models to reach balanced design standards that are suitable for the present time and to achieve sustainability standards.
\end{abstract}

KEYWORDS:

Entrances - Residential Buildings - Cultural Heritage - Sustainability Standards

\section{1- INTRODUCTION:}

The entrances of residential buildings are among the most important elements that constitute the design identity of the house in general, and it reflects many cultural, material, and intellectual concepts of those who live in it, and for the period that the residential building belongs to in general.

In the minds of the Arab community and the Egyptian culture, housing is considered the main pillar in helping to form a family, because it greatly affects the extent to which safety and stability are achieved for the family and then the community as a whole, and the house no longer satisfies only the need for shelter as it used to be in simple societies, However, in the eyes of the inhabitants, housing must combine the utilitarian and aesthetic elements and the elements of comfort to achieve the basic needs and psychological comfort of the inhabitants, and since the entrance is the first gate through which a person crosses from the external environment in which he deals with his peers competitively and cooperatively - so the social distance between them is uneven. Crossing the entrance, they immerse themselves in their personal spaces at all levels, and thus the entrance was and is still one of the most important parts of residential buildings in different eras and throughout different cultures and social levels. 


\section{INTERNATIONAL JOURNAL OF \\ DESIGN AND FASHION STUDIES}

VOLUME 4, ISSUE 1, 2021, 39-58.

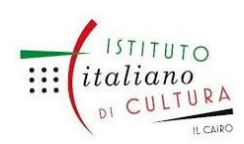

www.egyptfuture.org/ojs/

whoever contemplates the design of entrances of residential buildings in contemporary designs, notices that most of the designs take a character that is not commensurate with the standards of sustainability, or the achievement of fixed societal values, as most contemporary designs are directed to the outside, which gives a sense of disintegration and isolation, unlike housing designs and their entrances in the ArabEgyptian heritage, which received great attention from designers, and it had several characteristics that all work to achieve the principles of social and Islamic standards for the Egyptian society, Among the most important of them is the privacy criterion, in addition, we find many contemporary entrances houses designs ignore the sustainability standards that emphasize the preservation of resources, the use of local raw materials, and the saving of energy, as we find in many contemporary designs a trend towards extravagance and exaggeration in design elements to emphasize material aspects related to marketing elements for residential buildings.

The interior architecture designer has a major role in shaping the entrance element and designing it to suit the utilitarian and aesthetic needs of the inhabitant, to achieve the various design principles while preserving environmental sustainability standards, as well as emphasizing the identity of the community.

\section{2-RESEARCH PROBLEM:}

2-1 The absence of design standards that achieve the Egyptian and Arab identity in the design of contemporary residential building entrances.

2-2 Neglecting the important role of sustainability criteria in the design of entrances of residential buildings, especially in contemporary buildings, compared to the entrances of traditional residential buildings in the past.

\section{3-RESEARCH QUESTIONS:}

3-1 How did the designs of residential entrances for individual homes achieve the standards of sustainability in traditional Egyptian homes?

3-2 To what extent are the standards of sustainability achieved in the design of contemporary entrances?

3-3 What is the extent to which security and safety standards and other functional standards are achieved at the entrances of contemporary residential buildings, compared to the entrances of traditional residential buildings?

3-4 To what extent is the Egyptian and Arab identity linked to the design of entrances to residential buildings, in the past and present?

\section{4-AIM OF THE STUDY:}

The research aims to reach the most important principles of sustainability that must be achieved when designing the entrances of contemporary residential buildings and comparing them to the extent to which they are naturally and innately achieved, based on respect for the principles of the Islamic religion and the original Arab culture in the entrances of traditional housing and the need to preserve the Egyptian and Arab social identity in the design of contemporary residential entrances (Typical study: Al-Suhaimi 
house as a traditional house from the Ottoman era, and one of the models of the villas of Golf Yard in Madinaty, as a model for contemporary single residence).

Trying to extract the original foundations for designing entrances in traditional buildings and their compatibility with the principles of sustainability, and to apply them effectively to contemporary buildings.

\section{5-RESEARCH HYPOTHESES:}

Entrances in traditional residential buildings contain the most important standards of sustainability, Which has been achieved naturally and instinctively, applying of the teachings of the Islamic religion, and in fulfillment of the requirements of the prevailing Arab social culture, Despite lacking Many of these standards in contemporary entrance designs, which are directed towards other criteria far from the actual needs of the inhabitants.

\section{6-IMPORTANTS OF THE STUDY :}

Standing on the most important design and environmental standards that characterized traditional residential buildings to achieve a balance between basic contemporary design standards and preserving identity, and between observing and preserving the principles of sustainability in Egyptian residential buildings.

\section{7-DELIMITATIONS:}

The spatial range is Arab Republic of Egypt, Cairo Governorate, the temporal range is the Ottoman era and its comparison with the current era, the social boundaries of the research is the upper middle (rich) class in contemporary designs and traditional designs.

\section{8-PREFACE:}

The Arab Islamic house came to express the Arab-Muslim personality and is linked to several factors and influences that precisely legitimized the relationship between family members and the rest of the surrounding community, so the call to concealment and separation always had a great impact on the architectural form of the residences, as their external facades were heavy with few openings Like the veil that veils the residents inside the house, and it made its entrance broken, and special reception places are defined for visitors in it. The designer made it easy and have direct access from the closest point to the outside entrance, The steadfast residential buildings in the city of Cairo from the Ottoman era - which follows the designs of the Mamluk era - reflected all these meanings, as the Cairo community was distinguished in this era by dividing it into many classes - on top There was the upper class which includes the sultans and princes, and most of them inhabited palaces, and next to this class is a middle class consisting of senior employees and senior merchants where teachers and pens chiefs lived in independent private homes. The houses are called "Cairo houses". These houses represent the traditional residential architecture in Cairo from the late Mamluk era (1259 
- 1517) until throughout the Ottoman era (1517 - 1805), when the idea of private homes was widespread.

This was followed by a lower third layer in Cairo's society that consisted of several popular classes that included various segments of the craftsmen and craftsmen, small merchants, vendors, and the market. This class inhabited the combined residential buildings called "Al Raboua" until we reach the lowest segment of the popular class segments of those who have no work "The unemployed (Ghazwan, 2008).

Speaking of residential buildings architecture, by its nature, buildings are subjected to a lot of change and alteration, which is often linked to the tastes and moods of their owners who had their constant change in ownership of those Mamlokey and Ottoman homes (the foundations of modern ones dating back to more than five centuries) that had the effect of the weakening of these buildings, although the care for them are not interrupted, are much less in quality than the care received by the religious establishments due to their holiness and spiritual place ( Ghazwan, 2008)

Moving to the contemporary middle class, we find that the term "middle class" is flexible, elastic, and unclear, as it includes different social segments who live on salaries earned from the public and private sectors, and those who work in liberal professions, as well as intellectuals, middle merchants, and the greater part of state employees. Internal disparities in terms of the economic, social, cultural, and social status of those belonging to this class, and some divide it into three segments: lower, middle, and upper, which represent approximately $60 \%$ of the current demographic composition. (Hamzawey, 2012).

And the prevailing housing model, in the past and present, is either the individual or the group model, and the individual model in the past represented independent houses of one family, often for the upper-middle and rich class, while the collective model in the past represented the housing model for the low-income or below the middle class. Recently the individual model is represented in independent houses (villas) that are inhabited mostly by the rich, while the collective housing model represents - the traditional residential buildings inhabited by the majority of the Egyptian people of different classes and levels, as these collective units vary in diversity that serves all social strata at all levels.

The research presents two examples of the individual model of residential buildings, in the past and present, which were occupied by the wealthy class in the two eras. Moving on to talk about sustainability, we find that it represents a fundamental challenge, because it is one of the most important issues that must be taken into account in any type of architectural or interior design currently, and sustainable architecture means: that the architecture is a result of its environment and has a responsibility towards it, that is, it is 
an architecture that respects the resources of the earth and Its natural beauty is a building that "provides the needs of its users" if it leads to preserving their health, feeling satisfied, and increasing their production. It also takes into account "reducing the consumption of resources, materials, and energy" and thus leads to lower costs, in particular operating and maintenance costs, as well as It contributes to providing a safe, comfortable and harmonious urban environment in harmony with nature.

One of the most important goals in residential buildings - in particular - is to achieve social sustainability, and it can be defined as: "a comprehensive development strategy that seeks to empower people, build their capabilities and expand their options in various fields, especially social, political and economic, while affirming social equity and justice among the current generation or Between the present and future generations alike, and respect for traditions, norms, peculiarities and social identity as sources of enrichment for them.4(Gabeer, Alahbaby, 2011). (Gabeer, Alahbaby, 2011)

The most important design features of the "entrance" area will be studied in the historical traditional residential buildings compared to contemporary residential buildings, through the study of two models (for individual housing), one of which is traditional dating back to the Ottoman era, and the other is contemporary in a new urban community in Cairo.

It represents a model of private homes inhabited by one family, and the majority of those dwellers are from the upper-middle and wealthy classes. The facilities during the period of the Ottoman rule were generally characterized by their relatively small size compared to their pre-eras, as the area of the Ottoman homes was less than the Mamluk, while retaining many architectural and design characteristics, and was distinguished by the distance from the simplicity and the tendency to luxury and attention to the general form.

\section{First: Example of Heritage Residential Buildings:}

\section{Sehemi House:}

It is the monument No. 339 (the Ottoman era), built on an area of half an acre, and this house is located in the Al-Darb Al-Asfar neighborhood, branching from Al-Muizz Li Din Allah Street in the Jamaliyeh neighborhood in Fatimid Cairo, and the credit for its establishment goes back to Abd al-Wahhab al-Tablawi (1058 AH / 1648 CE) and Ismail Ibn Haji Ismail Shalabi who completed construction (the year 1211 AH / 1797 AD) Ismail Ibn Haji Ismail Shalabi who completed construction (the year 1211 AH / 1797 AD). ( Ghazwan, 2008) Fig. (1),(2),(3) 


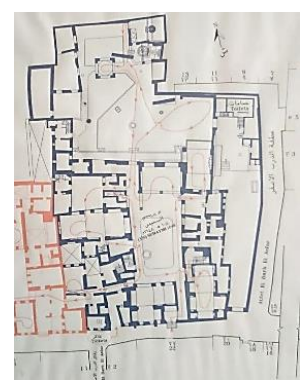

Fig. (1) plan of gound floor of Sehemi House

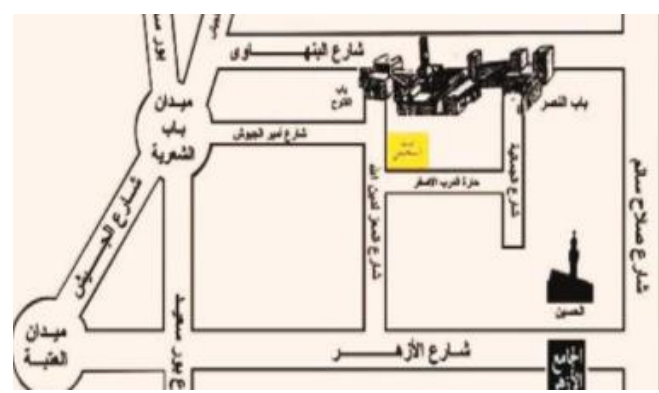

Fig. (2) layout of Sehemi House(shaded in yellow)

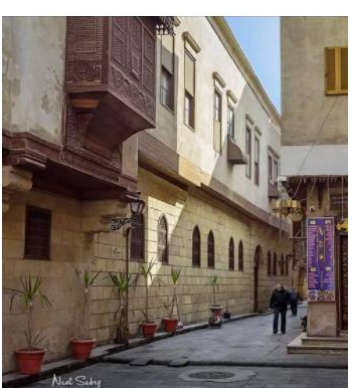

Fig. (3) Eldarb Elasfar Lane

1-The Main Entrance: Isolated from any visual extension of the homes of others, and the entrance façade represents the veil that protects the residents of the house from the eyes of strangers. The walls of the facade were distinguished by the height of the door of privacy and the preservation of the rights of the neighborhood. (Albeldawy,2016) The house has two entrances, one for the household and the other for guests and men. . Fig. (4),(5)

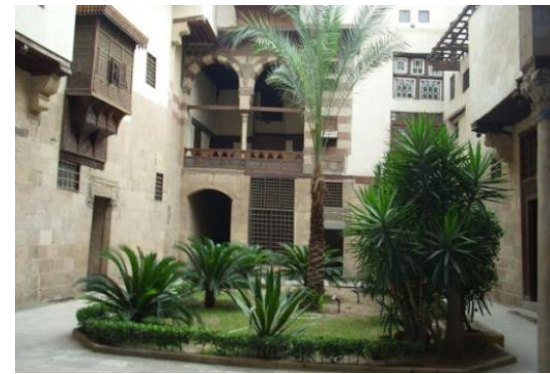

Fig. (4) A view of the inner courtyard of Beit Al Suhaimi after entering the entrance corridor

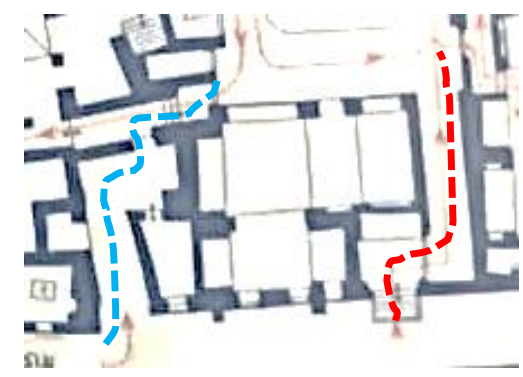

Fig. (5) The main entrance to the house in red, and the branch entrance (used to book tickets now)In blue (and both lead to the inner courtyard)

1.1 The house is open to inside: Where access from the door and the corridor leads to the open patio, which works to bring together the people of the house and to cool down the temperature and the great psychological comfort resulting from the presence of plant and water elements and natural materials.

1.2 Relation to surrounding urban space: The external doors of the entrance do not face similar entrances to the houses opposite them in the general planning of the street, so that the neighbors do not reveal any part of the internal parts of the house. This is known as "fitting doors. (Abaalla, 2012)

\section{2-Entrance elements :}

\subsection{The refracted entrance (the bashura-al-majaz):}




\section{INTERNATIONAL JOURNAL OF \\ DESIGN AND FASHION STUDIES}

VOLUME 4, ISSUE 1, 2021, 39-58.

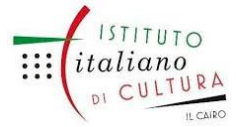

www.egyptfuture.org/ojs/

It is a space or a corridor separating the inside from the outside and forcing the inside to turn right or left (at an angle of 90 degrees) to block the inside of the house, and preserves the privacy and privacy of the inside, and leads to the open courtyard and the rest of the housing elements through which the inside can see the outside and not vice versa And it provides protection to the house from outside noise and dust, and it leads to the entry of air into the house by leaving it open, and the entrance to break is simple or weak according to the family's standard of living Fig.(6)
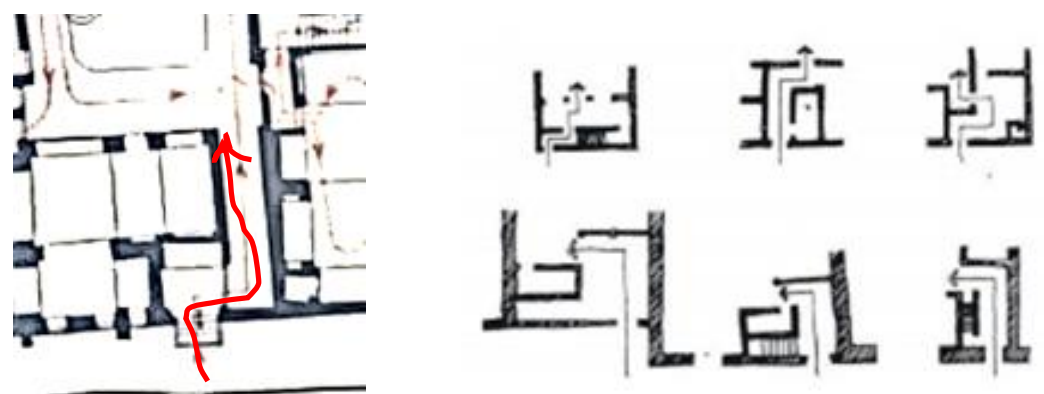

Fig.(6) The broken entrance to the House of Sahimi to the left, And models of the weakened Islamic entrances to the right.

2.2 The shed (or darka-darkaa): And the plurel is (Darkawat), which is a Persian word in origin, is given to the square or rectangular area immediately following the entrance and through it to reach the interior of the house, and thus it is a transitional space, enabling the people of the house to prepare, to receive their guest, or for the visitor until he catches his breath, pending the permission of the people of the house to receive it or reject it Facing the darkroom, there is a floor for the guard of the house to sit. Figure (7) 2.3 Entrance Vertical Level: The house had several steps up, but with the passage of time and the accumulation of layers of the outer street - those layers disappeared and turned into two steps that are used to go down inside the darkness.

2.3 External doors: There is a main external door that opens to the inside and closes with a single leaf (leaf) made of solid wood laminated with iron and nails.

- Door Type: "arched door" meaning that is covered by a semicircular arch or part of a circle (9), and it is also a "applied door" (massif), meaning that it is a wooden door whose main structure consists of wooden panels with a dowel that intertwine the panels with each other. It has strips of iron on it. It has large iron nails that collect the door beams, and give it an aesthetic shape besides the structural function. Fig.(8),(9) 


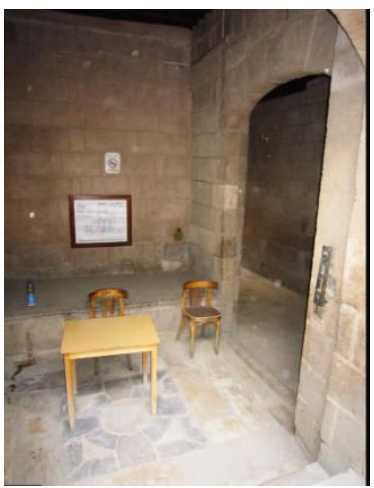

Fig. (7) Darkaa of Beit Al Suhaimi which lead to the vestibule and the mastaba

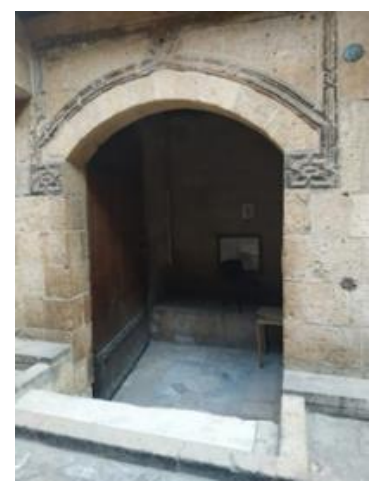

Fig. (8) Entrance to Beit alSahimi (the door with one leaf).

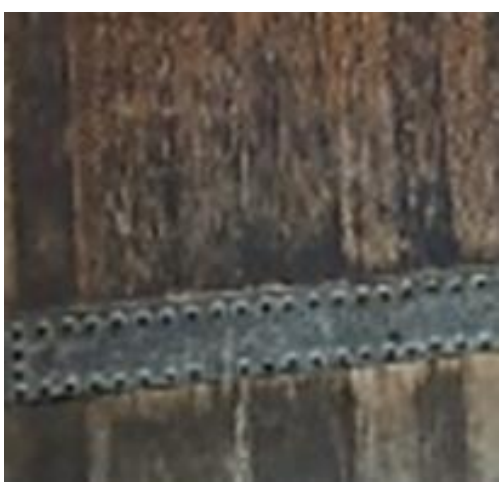

Fig. (9)Details of the leaf of the door of Al-Sehaimi House.

- $\quad$ The Knocker: The door was equipped with an elegant knocker made of iron or copper (the same as the rest of the houses at that time) touched by the guest to ask permission to enter the house. Fig.(10)

The Knocker or al-Maqarah is considered one of the Arab artistic heritage, and the hammer is a small metal tool that is attached to the door from the outside, so that it can be moved and knocked on a metal base to make a sound heard from inside the house in order to open it to visitor.

The hammer plays an important role in the etiquette of entering the home, imposed by the religious factor, whereby the hammer achieves permission to enter, and the need for a loud call is eliminated. It is also the first thing that the guest touches, and what he sees from the house, and the knocker of the door was a welcome field for artists, makers and craftsmen, for innovation and creativity (Shaheen ,2021)

2.4 Corridor : the door after the porch leads to a long and narrow corridor to achieve the purpose of separation and concealment, and to prepare the house for the reception. This corridor leads directly to the courtyard. Fig. (11)

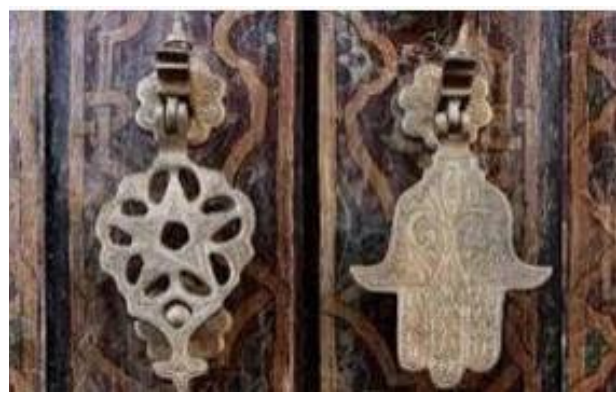

Fig. (10) the traditional hammer.

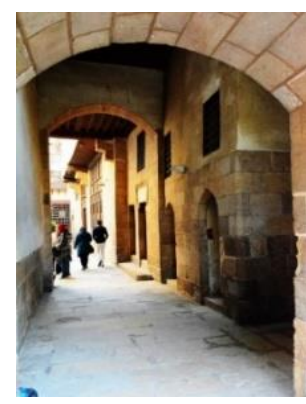

Fig. (11) the corridor of the of $\mathrm{Al} \mathrm{Shemi} \mathrm{house.}$

\section{3- Security at the entrance:}

Muslims have taken several means to secure the doors, including: 


\section{INTERNATIONAL JOURNAL OF \\ DESIGN AND FASHION STUDIES}

VOLUME 4, ISSUE 1, 2021, 39-58.

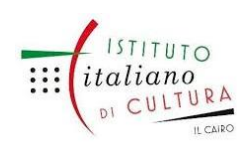

www.egyptfuture.org/ojs/

3.1 The latch(Almezlag): it is a longitudinal strip of iron with which the door is closed without a key, which is fixed to the face of the moving door shutter from the inside, and its weight is sufficient to settle in another iron hole in the door box, or in the second fixed shutter, and it can be Moving it from the outside with a thread that is raised when opening and lowered when closed, so the protruding end falls into the core of another iron fixed in the fixed shutter of the door. Fig.(12)

3.2 Plating the door shutters with laminate: It is a technique that increases the durability and stiffness of the door and the connection between its parts and the aesthetic shape. Fig.

3.3 Door locks (dabba) (osama ,2016):- It is one of the basic elements of the door from inside or outside the house, usually from outside the house, and it is made of wood and also has a key from wood. The carpenter is interested in making the dabba and its decoration according to the request of the owner of the house and his ability to pay for the industry wage. Fig. (14)

3.4 Al-Razza: (osama ,2016) It is an iron piece in which the key is inserted, which is what opens the door(Shahen ,2010). Fig. (15)

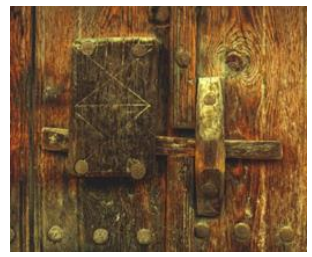

Fig. (12) One of the vernacular shapes of The door ratchet made of wood.

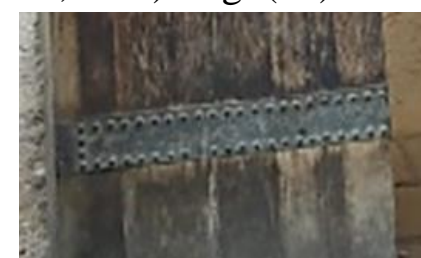

Fig. (13) Plating laminate door shutters.

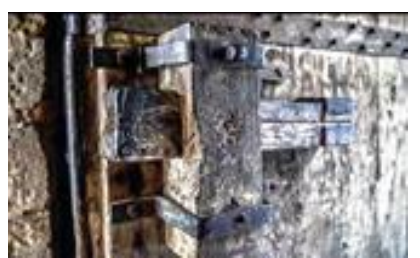

Fig. (14) Al-Daba in the door of his agency Kohl aesthetic - Ottoman era.

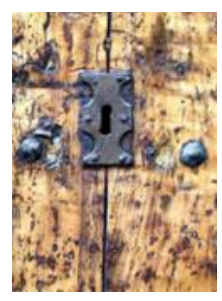

Fig. (15) forms of metal splash on doors.

4-Insurance and control: The means of insurance appeared clearly in the Mamluk state since its inception, as the Mamluk princes took care of fortifying their palaces to withstand the attackers, so that some of them provided some defensive architecture elements, such as the tower, which still provided the original main entrance to the palace with openings (Almazaghel slot)( It means a narrow opening in the city wall, castle, or tower, and arrows are fired from it, as they were used at the same time for ventilation, lighting and surveillance) and control, Likewise, the spindle opening, which is still present near the secret door of the secondary entrance to the palace of Prince Taz, and those defensive security means in the Ottoman homes such as the Suhaimi House shrunk to stabilize the security conditions (relatively), and they relied on increasing the thickness and durability of the external walls, so its thickness was up to $50 \mathrm{~cm}$. (Zaher,2015) .Fig. (16) 


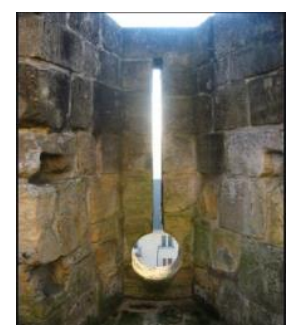

Fig. (16) Almazaghel slot

\section{Second: Example of contemporary residential buildings:}

The model of individual homes in the modern era often represents upper class (wealthy) homes where they live in private villas, whether they are in the heart of the city (there are only a few of them to turn most of them into multi-storey collective residential buildings) or in the suburbs, or in new urban communities such as Madinaty and AlRehab On Suez Road, Cairo Governorate.

\section{A villas in Madinaty:}

Model (B) Golf Heights Villas in the second region. - The area is 615 square meters, and construction of Madinaty started in July 2006, on an area of approximately 33.6 million square meters, which makes this project classified as the largest closed city with integrated facilities and services in the Middle East. The project is expected to be fully completed by 2023.

Three of the major American companies specialized in designing new cities participated in its design, namely HHCP, SWA , and SASAKI International. Fig. (17),(18),(19)

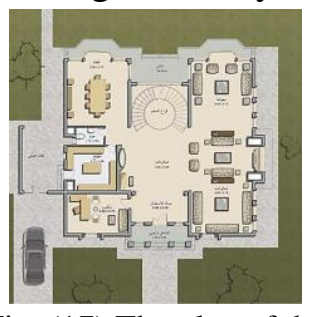

Fig. (17) The plan of the ground floor of the B model in madinaty .

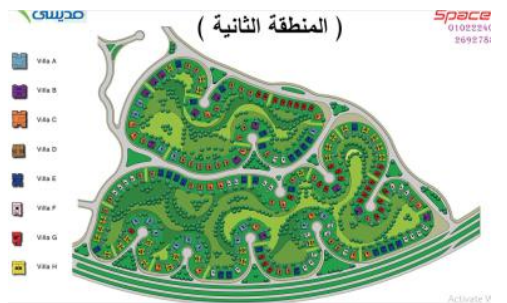

Fig.(18) General location of Golf Heights Villas

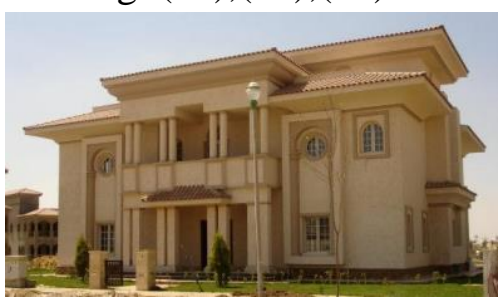

Fig .(19) The chosen model

5- The main entrance: It is located on the main facade of the house and leads directly to the reception hall and the salon area. The house is not surrounded by a high flat wall, but rather a relatively low-rise wall of wrought iron and shrubs, whose height varies according to the desire of the owner of the house. The villa has two entrances, the main entrance and the secondary entrance for service from the kitchen area. Fig.(20) 
The house is open to the outside: entering from the door of the house leads to the reception and living space, and exiting the door leads to the garden of the house, psychological comfort, botanical elements, and natural materials. Fig.(21)

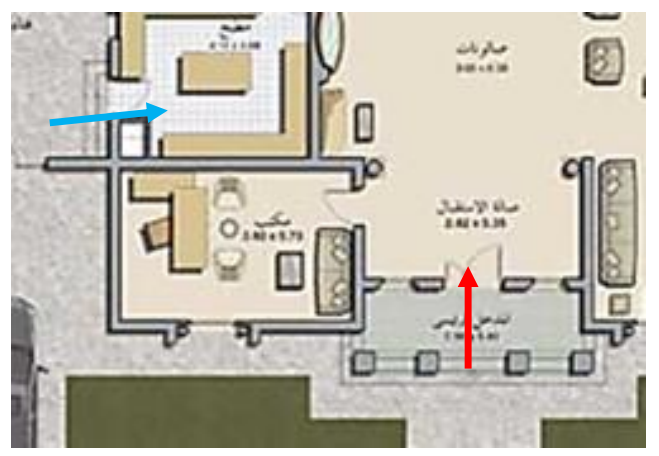

Fig. (20) Direct main entrance - and the Secondary one (from the kitchen to Villa Madinaty)

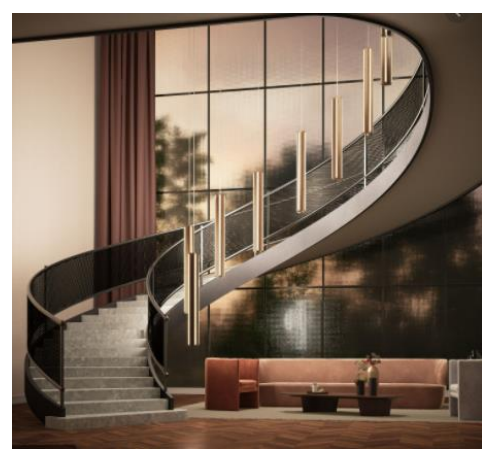

Fig. (21) a view of the reception area after entering the door in Villa Madinaty

6- The relationship to the surrounding urban space: the entrances are not exposed, as the distance between the house and the road for the traffic of cars reaches 6: 8 meters, and it consists of the front garden of the house, and the entrances in general do not face each other in addition to the great breadth of the street.

\section{7- Entrance Element:}

7.1 Broken Entrance (Bachoura - Al Majaz): Modern villas do not have a trace of broken entrances, as the entrances directly face the external doors and are located on one axis with them, so the interior of the house reveals all parts of the house from the first glance.

The entrance hall can be designed in several ways, taking into account the presence of some basic elements, as The entrance contains a basic distribution space that leads to the main traffic corridors, and it must be separated from the living space to achieve the required privacy, and it can contain other secondary elements such as places for hanging heavy clothes, places for shoes, places for keys, the main attraction element (Consol - Mirror Flowerpot ....), spotlight, one or two seats. Fig. (22) a,b.

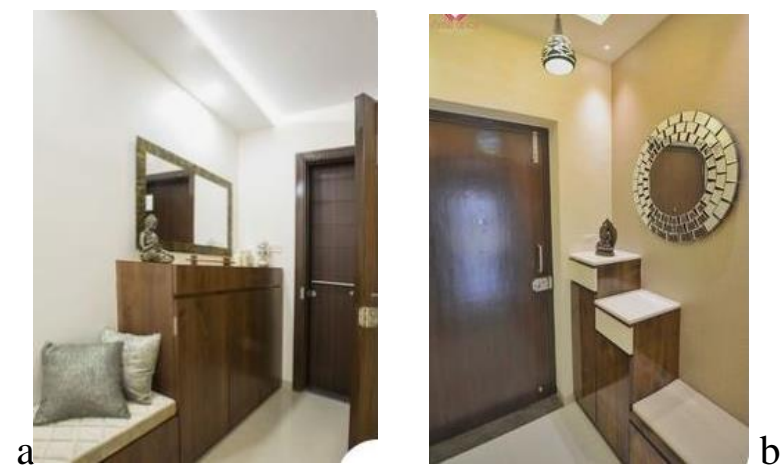

Fig. (22)a,b the design of the entrance hall reception 
7.2 The shed (or darkaa): The traditional shed has no presence in the contemporary model, and it is replaced by the introductory architectural element at the entrance which is the preliminary space (approximately $5.0 * 1.20$ meters) with a high level outside the entrance, which is a part of the roof that is high with four steps of stairs surrounding the entrance that paves the connection between the inside and the outside and is shaded Through the balcony of the first floor and supervised by four identical columns that divide the entrance pre-area into three spaces, the middle of which is a main and two secondary sides .

7.3 Entrance Level: The house has a height of up to 4 degrees of $60 \mathrm{~cm}$, and a slope can be implemented in all residential models according to the request of the owner. Fig. (23)

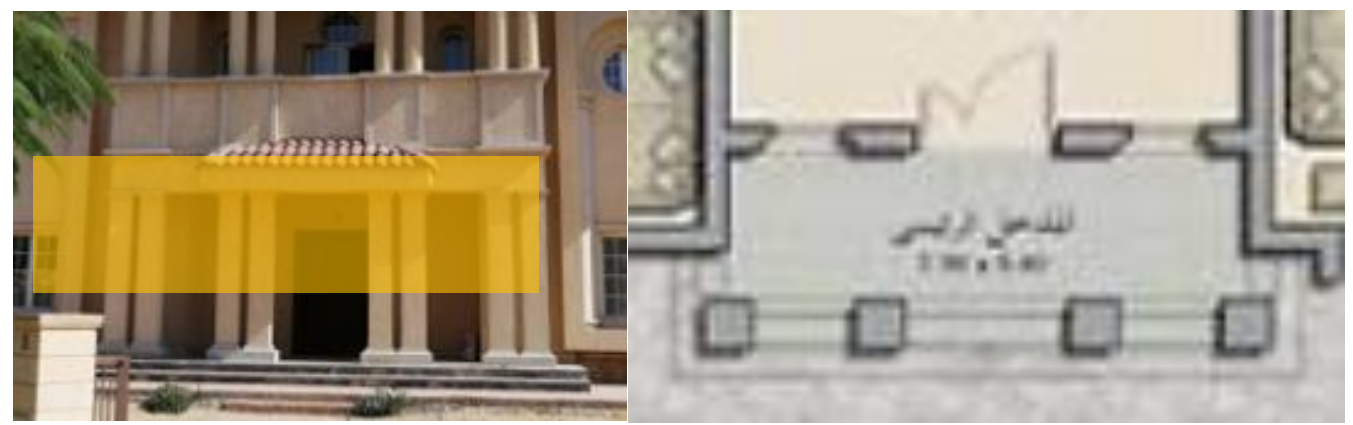

Fig. (23) The introductory space with a high level outside the entrance of Villa Madinaty.

7.4 External doors: The entrance consists of a double-sided door, one $90 \mathrm{~cm}$ and the other $40 \mathrm{~cm}$.

The types of wood used in it vary between natural and manufactured. And one of the most common types of doors is armored doors.

- And it has many types - and its specifications are as follows:

It is made of some carbon steel, it has 11-19 centers of closure, it is manufactured by sandwich panel system, thickness is $55 \mathrm{~mm}$, and it consists of two layers of carbon steel Layer thickness: 1.2: $2.0 \mathrm{~mm}$ with internal support for the entire length of the door with 23 supports (Depending on the width of the door), the main movement centers are supported by a longitudinal U-shaped box, clad on both sides with MDF panels covered with natural wood veneer.

Ring components: the door is installed by 2 special rings of steel thickness of $5.5 \mathrm{~mm}$, the first is called the initial ring (Subfram) (buried) is an angular section $6 * 5 \mathrm{~cm}$ for fixation in concrete or buildings with 8 canes of steel or with cement, and the second is called the final ring (Mainfram) It has a corner section for hanging armored doors and operating the sash and the door - fixed by two steel hinges. Figure (24),(25). 


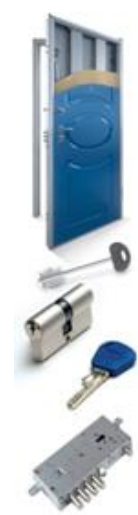

Fig. (24)

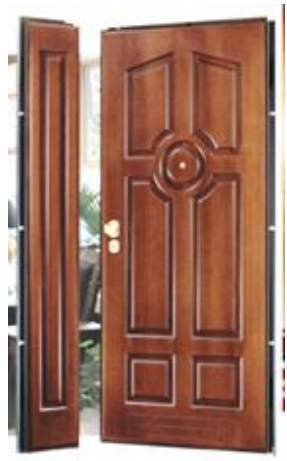

Fig. (25) Models of laminated double-sided doors covered with natural

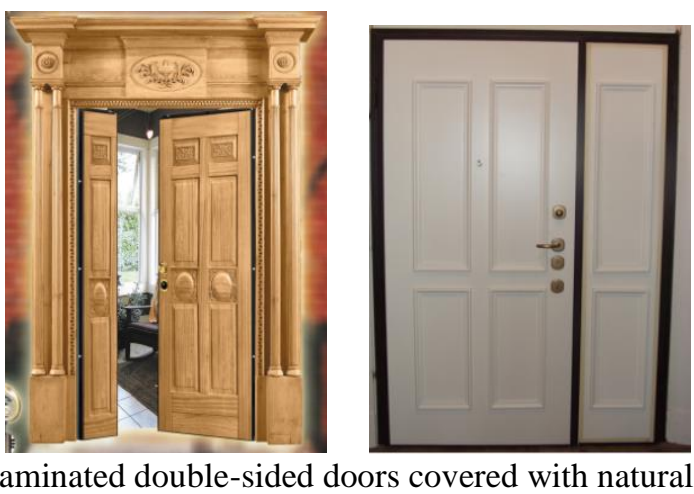
wood veneer.

Armored doors.

7.5 Doorbells instead of The Knocker: Modern doorbells are electrically operated and actuated by a button switch. Modern doorbells often include intercoms and miniature video cameras to increase security.

- Smart doorbells:

It is used in the doors of homes and villas since the widespread use of the Internet in 2010, and the system consists of one unit located instead of the traditional button for the bell, and it contains a high-resolution camera, a passive infrared sensor, and electronics (wi-fi) and the device is connected to the home internet network, and it is done Send notifications of a button press or a detected movement.(Smart doorbell,2021).

Turn it into a smart phone or other electronic device such as a homeowner's tablet. Thus, the owner sees a live video broadcast that shows the visitor's personality at the door of the house and allows for a two-way voice conversation. Fig.(26)
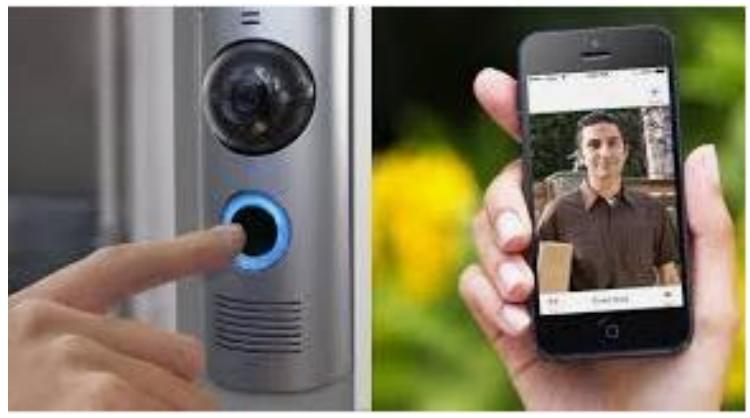

Fig.(26) Smart doorbells

7.6 The vestibule: the vestibule expresses the content of the Arab traditional (darkaa), which is the interior hallway of the house in preparation for entry. Many villas cut-off part of the external space of the entrance for it, or allocate a part next to the entrance door and lowering the roof and creating internal light walls for separation and preparation, or by implementing it in a light way that requires only the placement of a partition 


\section{INTERNATIONAL JOURNAL OF \\ DESIGN AND FASHION STUDIES}

VOLUME 4, ISSUE 1, 2021, 39-58.

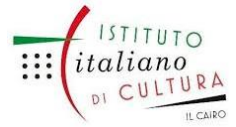

www.egyptfuture.org/ojs/

separating the internal space and A borrowed floor and ceiling in different styles. Fig. (27), (28),(29) .
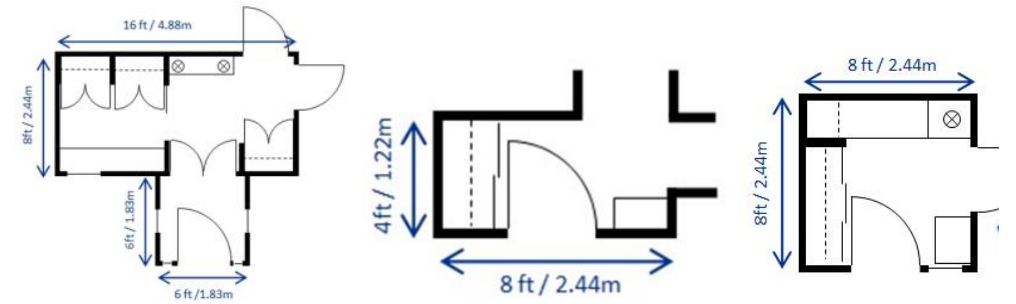

Fig. (27) plans of the interior hall spaces that are physically separated from the internal space of the entrance.( Escott, 2021)
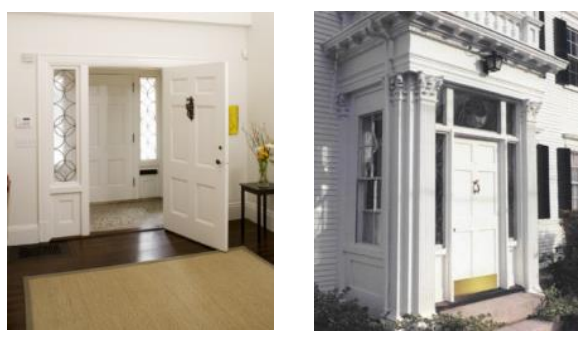

Fig. (28) The internal lobby spaces as part of the internal space or the external space of the entrance.
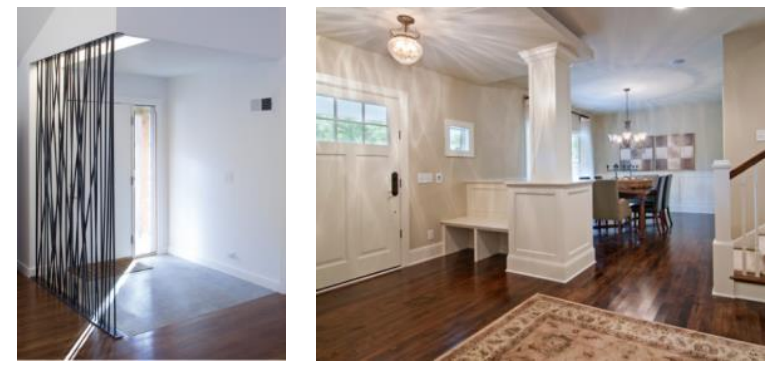

Fig. (29) The formation of the internal vestibule on the internal reception space by its relatively distinctive features that allow partial separation and limited privacy of the entrance from the rest of the spaces .

7.7 Security at the entrance: The use of armored doors and they are equipped with a central cork that works horizontally and vertically to close, and it contains 6 movable closing centers +5 fixed centers.

The door is provided with an insulating leather gasket and a rock wool filling, thus it is considered sound, heat, smoke, and smoke-proof. There is also a brush under the door that works mechanically when the door is closed to prevent insects from entering and dust leakage.

- $\quad$ Electronic door control: (Access Control): It is a system that allows controlling the electronic locks of doors of all kinds and determining the persons authorized to pass through these doors, and the system records all the movements of persons inside the 
facility from the first entry to their exit and records their movements through all other internal doors. Figure.(30)

The system grants powers to specific people to open specific doors through one or more options, including fingerprints, fingerprints, smart cards, smart chips, or passwords, and this ensures the provision of high levels of security.

The system controls the period time in which the doors are allowed to be left open, provided that action is taken such as operating warning sirens, sending an alert to computers, or taking other measures that provide the facility with the required level of security, and it is also possible to control the operation of alerts when trying to open one of the doors by force or attempt It is opened by people who do not have the authority to pass through these doors.

- Insurance and surveillance: surveillance cameras: Advanced cameras are used as a security system for the gates of large homes and villas that provide high-definition picture quality (such as accurately displaying people's features, identifying faces, car plates, etc. Pictures and videos are preserved on digital recording devices, and the cameras have night vision even without lighting. Using infrared and other advanced technologies and algorithms, some cameras provide a 360-degree viewing angle, including those that have different lenses that can focus and zoom.( Door security,2021)

The advanced cameras contain motion sensing and motion tracking technologies that monitor the movement that occurs in a specific place and take a specific action, such as starting a video recording, taking a picture and sending it by e-mail, or triggering the alarm to alert and other measures that are implemented either through the cameras directly. Or through other devices that work in an integrated way with the system. Fig .(30),(31).

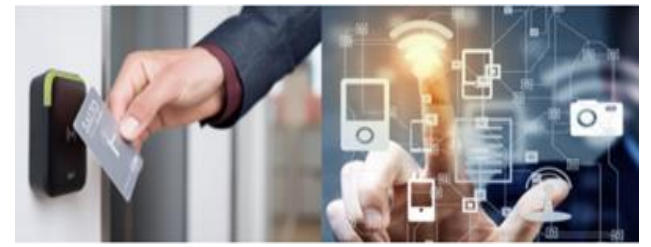

Fig. (30) electronic control of doors

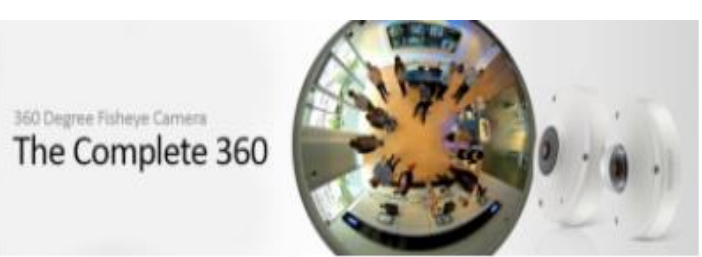

Fig. (31) Surveillance Cameras

\section{8- Achieving the principles of sustainability in both the traditional and contemporary model: Table (1)}

Comparison between the traditional and contemporary model in terms of the extent to which they achieve sustainability standards. Table (1)

\begin{tabular}{|c|c|}
\hline Contemporary residential buildings & Traditional residential buildings \\
\hline \multicolumn{2}{|c|}{ 8.1The principle of preservation and continuity } \\
\hline $\begin{array}{l}\text { The principle does not exist - the house of } \\
\text { parents and grandparents is often left by the }\end{array}$ & $\begin{array}{l}\text { Homes are designed to grow and expand } \\
\text { horizontally and vertically according to }\end{array}$ \\
\hline
\end{tabular}


children and grandchildren and heading to other sites and perhaps they will migrate in search of work or the required social level, and the durability of the building is linked to the efficiency and conscience of the executing contracting company, and consequently, the houses do not last for successive generations as it used to happen. In the past, and if it persisted, it did not suit the tastes, needs, and aspirations of new generations.

need and according to the evolution of the number of family members. One house is inhabited by generation after generation and when needed, ownership passes from one family to another so that the house is inherited by the new family - and this is consistent with the essence of sustainability so that the resources are used generation after generation. A generation later, the strength of the construction was acclaimed by the well-established stonebearing wall systems.

\subsection{At the level of the general planning of the neighborhood}

At the level of general planning for the neighborhood in which the house is located, the planning is far from the idea of the solidarity fabric, as the spaces between the villas and some of them are very large to achieve the principle of (privacy), which led to the waste of resources (land area) to a large extent the allocation of large areas to a limited number of owners And their social estrangement has also led to their isolation from each other in distant islands without any connections between us. Fig.(33)
At the level of the general planning of the neighborhood in which the house is located, the theory of the compact city or the compact fabric is realized (meaning here is the distance from dispersion, divergence, separation, and division) where the streets are divided into a group of disparate spaces that reflect the means of social expression and form the identity of the community, and the division of the land is subject to social criteria based on it. Social solidarity and cooperation among members of society in a single organic pattern that takes into account the needs of people in employing the appropriate areas of land for construction without extravagance in the lands used in construction (to preserve resources) with the existence of the principle of convergence, solidarity and social communication between the owners of different homes. Fig.(32) 


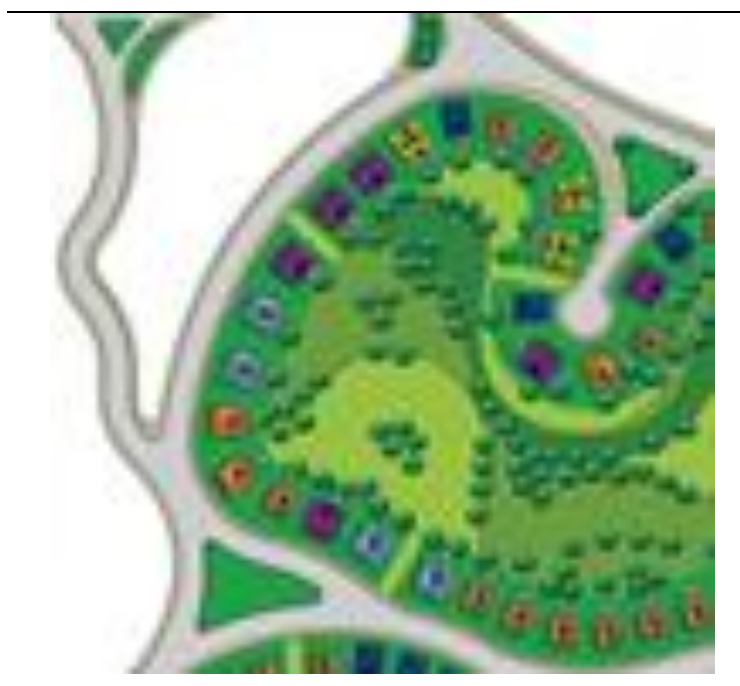

Fig. (33) the relationship between the land area used for housing and the separating spaces between the dwellings under the pretext of privacy, which led to the use and consumption of large areas of land (as a resource) to serve a limited number of consumers.

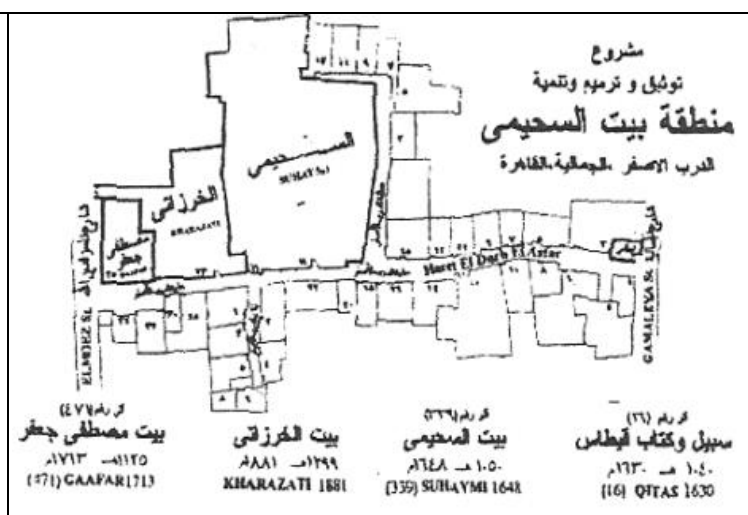

Fig. (32) The relationship of Beit Al-Sehaimi with the surrounding urban vocabulary, which supports social communication.

\subsection{Entrance Privacy}

The design is less than the traditional one $\quad$ The design includes an affirmation of the in confirmation of the privacy principle. principle of privacy.

\subsection{Keeping away from pollution}

The principle of openness to the outside reduces the chances of preservation from external pollutants. The house breath outside (the garden) is the area of the house that is more integrated with the external environment, audio, visual and respiratory. It helps to reduce pollution by choosing a high tree density for the trees of the house fence, while choosing types that impede the dust and purify the air, such as casuarina, eucalyptus, cypress, pine, and acacia.
The principle of openness to the inside associated with the entrance achieves the reduction of pollution through the distance at the entrance from the direct and the contiguity with the external road, which contains the elements of pollution with soil and gases from the movement of cars and pedestrians, in addition to the presence of plants in the yard that limits the impact of pollutants, as well as separating the entrance area and Going inwards from the external audio and visual pollution. Maintaining and improving the health of individuals is one of the most important principles of sustainable design. 


\subsection{Preserving the internal climate of the house}

The building has a structured type and the entrance walls are $20 \mathrm{~cm}$ thick of solid cement bricks, which allows the transfer of thermal radiation into the house easily and thus increase

The need for air conditioners most hours of the day, which increases energy consumption, in contradiction to the principles of sustainability.

Or it requires thermal insulation of the external walls by using foam materials that compensate for the lack of thickness of the walls or the non-use of hollow bricks or double walls Fig.(34)

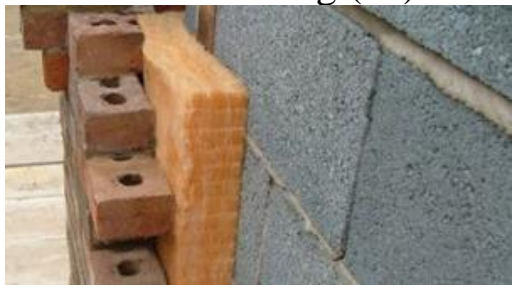

Fig. (34) the use of foam materials for thermal insulation For walls and the construction of a secondary wall half a brick for cladding.
The house is built with limestone with a thickness of $50 \mathrm{~cm}$ and more, and because of the light color of the stones, they reflect a large part of the solar radiation falling on them, and the limestone is a material with a high heat capacity, as its density is large $(1920 \mathrm{~kg} / \mathrm{m} 3)$, which makes the thermal penetration time through it up to 15 hours (Wazery, 2011), and this means that the external heat will take a long time to reach the internal voids of the building due to the nature and thickness of the stone used in building its walls, which maintains the temperature inside the house. This achieves one of the most important principles of sustainability, which is to reduce energy consumption.

\section{9- Conclusion:}

Through studying the model of Al- Suhaimi house, comparing it to the model of one of the villas in my city and discussing the elements of the entrance area in terms of achieving the principle of continuity in the design, the general planning of the neighborhood that contains the entrance, achieving the principle of privacy at the entrance, keeping away from pollutants, and preserving the temperature and appropriate weather conditions, it was found that the model The traditional Islamic residential buildings are represented by the house of Al-Suhaimi, which has the elements of sustainability well in terms of the continuity of construction and its use from generation after generation, and the relationship of the entrance to the general planning of the street and the surrounding urban vocabulary, achieving the principle of privacy in the entrance, preserving the house and keeping away from external audiovisual pollution, and maintaining the internal temperature, which confirms to us the necessity of preserving the inherited traditional thought in housing design and trying to achieve it in a contemporary way in designing the entrances of residential buildings to achieve the great benefit at the level of design and sustainability. 


\section{0- Main Results:}

10-1 Despite the simplicity of housing in the traditional Islamic eras, it achieved a unique model for community sustainability by ensuring the preservation of privacy and the preservation of rights.

10-2 The entrances to the traditional residential buildings represent a model for achieving environmental sustainability, as they formed a system that is immune to the elements of air pollution, audio pollution, and visual pollution.

10-3 Traditional house entrances contribute to preserving the internal climate and reducing the bad external weather conditions, which reduces energy consumption in homes and significantly confirms the achievement of the principles of sustainability.

10-4 Simulating the traditional Islamic system in dividing spaces and sequencing them increases the effectiveness and glamor of contemporary interior designs and serves functionalism and achieving privacy in dwellings.

\section{1- Main Recommendations:}

11-1 The necessity of preserving the basic principles of planning traditional residential buildings due to the preservation of human social rights, and the preservation of the environment and its resources for future generations.

11-2 The importance of establishing the design elements that preserve the Arab identity, as this preserves the established values and principles that preserve the rights of the individual, society, and the environment as a whole.

11-3 Achieving the principles of sustainability in contemporary designs is not incompatible with preserving the identity. The two must be blended to achieve the complete picture in terms of integration between the exploitation of modern technology elements and the preservation of the community's legacies and resources.

\section{2- Main References:}

\subsection{Arabic References :}

1-Ghazwan Yaghi, The Importance Of The Remaining Mamluk Residential Buildings In Cairo And The Factors Affecting Their Design, Ph.D., Islamic Archaeology and Art, Cairo University, Faculty of Archeology, Department of Islamic Archeology,p:204

2- Amr Hamzazi, Article (The State of Egypt - The Middle Class), El-Shorouk Newspaper, Tuesday, February 23, 2021.

3- Saba Jaber Nehme, Shaima Hamid Al-Ahbabi, published paper (Mechanisms for achieving social sustainability in the traditional urban structure) Engineering Journal, Volume 17, Issue 3, June 2011.

4- Al-Baldawi, Thabit, The Islamic Concept of the Residential Interior Space (Analytical Study of Samples of Islamic Palaces) Published paper - Department of Interior Design College of Architecture and Design - Al-Ahliyya Amman University - Jordan, Zarqa Journal for Research and Human Studies, Second Issue, 2016. 


\section{INTERNATIONAL JOURNAL OF \\ DESIGN AND FASHION STUDIES}

ISSN: $2735-5365$
VOLUME 4, ISSUE 1, 2021, 39-58.

5 -Nour Al-Din bin Abdullah, Practical Applications of the No Harm and No damage,

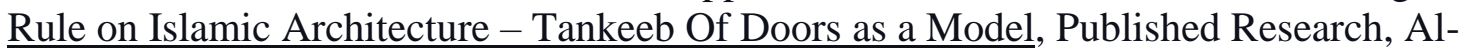
Qalam, Al-Hikma Magazine, Dar Al-Nizamah, 2012, p. 253

7- Osama, Ahmed, Visual Vision Through The Folklore "The Dapaa And The Fall By Using Prominent Printing", November 2016

8- Waziry, yhya, Islamic Architecture, and the Environment: The Tributaries that Shaped Islamic Reconstruction,2011,p:107

\subsection{Web Sites:}

$$
\begin{aligned}
& \text { 1. روائع الفن الإسلامي في مصر ..أبواب المساجد فن الحضار ات ات }
\end{aligned}
$$

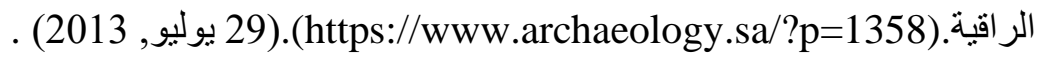

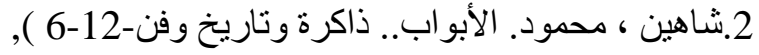

$$
\begin{aligned}
& \text { 2010).(https://www.albayan.ae/paths/books/2010-12-06-1.593971) }
\end{aligned}
$$

3. Zaher,Alla-elden,(10-1-2015).(http://atharmasr.blogspot.com/2015/01/blogpost_36.html)

4. Door security.( 30 May 2021).(https://en.wikipedia.org/wiki/Door_security)

5. Smart doorbell.(24 January 2021).( wikipedia),(https://en.wikipedia.org/wiki/Smart_doorbell)

6. Escott, Meg. Foyer Design.(10-3-2021).

(https://www.houseplanshelper.com/foyer-design.html) 